\title{
The Role of Homoaromaticity in the Tropylium-Catalyzed Carboxylic Acid O-H Insertion with Diazoesters
}

\section{Anakuthil Anoop,* Venkataraman Ganesh*}

Department of Chemistry, Indian Institute of Technology Kharagpur, Kharagpur

West Bengal -721302, India

anoop@chem.iitkgp.ac.in; ganesh.v@chem.iitkgp.ac.in

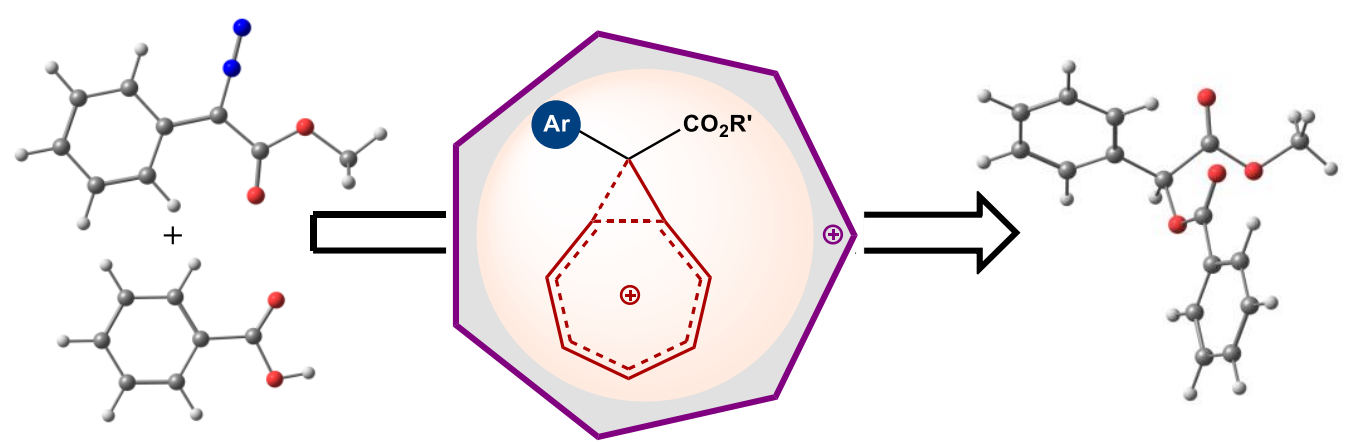

Homoaromatic Intermediate

\begin{abstract}
The tropylium catalyzed carboxylic acid $\mathrm{O}-\mathrm{H}$ insertion with diazoesters providing $\alpha$-hydroxy esters was reported recently through an activated carbene as the key intermediate. We report a revised mechanism involving a unique homoaromatic intermediate with the tropylium ion and the diazoester based on the DFT calculations. Our computational model provides a clear insight into the binding of the tropylium ion with the diazoester providing the homoaromatic intermediate. The reaction profiles of four different pathways were compared. The energies of the intermediates and the transition states are reported at B97-D3(SMD)/def2TZVP//B97D3/def2TZVP (in dichloromethane). The energy profiles were compared across a few computational methods to study the sensitivity of our model across methods.
\end{abstract}

Keywords: Tropylium ion catalysis, homoaromaticity, non-classical carbocation, diazoester, $\mathrm{O}-\mathrm{H}$ insertion reaction. 


\section{Introduction}

Lewis acid catalysis is an indispensable and ubiquitous route in building complex natural product skeletons. The diversity of Lewis acids has facilitated a variety of Lewis acid-catalyzed transformations like the Diels-Alder reaction, Friedel-Crafts reaction, ene-reaction, carbocation-mediated reactions, addition to carbonyl compounds, and so on. ${ }^{1}$ Despite their prominence, the carbon-based Lewis acid catalysts, i.e., carbocations, are not well-studied due to the inherent challenges in the accessibility of the catalysts, control on reactivity, low stability, and low catalyst turnover. Only a handful of carbon-based Lewis acid catalysts has been efficiently used in organic transformations ${ }^{1 \mathrm{c}, 2}$ viz., cyclopropenyl cation, ${ }^{2 \mathrm{~b}}$ tropylium ion, ${ }^{2 \mathrm{a}, 3}$ trityl cation. ${ }^{2 \mathrm{c}}$ Among these carbocations, the cyclopropenyl and tropylium ions are stabilized by aromaticity, whereas the trityl type cations get stabilized by the resonance effect. Mayr's electrophilicity scale has been a valuable tool in designing the desired catalyst with the right balance of stability and acidity. ${ }^{4}$ The pioneering works of Olah, Breslow, and Doering on the non-classical carbocation chemistry, ${ }^{5}$ cyclopropenyl, ${ }^{6}$ and tropylium cations are noteworthy. ${ }^{7}$ Using these underlying concepts, Lambert and coworkers popularized the use of aromatic carbocation as carbon-based Lewis acids to mediate various transformations. ${ }^{2 b, 8}$ The stability offered due to aromaticity provided the necessary control and the ability to increase the catalyst efficiency. However, aromatic cations like cyclopropenyl and tropylium cations as Lewis acid catalysts lose their aromaticity momentarily in the intermediate steps due to coordination with the substrate making these steps endothermic. On the other hand, the stabilized aromatic carbocations overcome the challenges of catalytic turnover and control over the reactivity faced by the carbon-based Lewis acids.

The tropylium ions have recently gained enormous attention as an efficient carbon-based Lewis acid catalyst and mediate various organic reactions. ${ }^{2 a}$ The pioneering works by Nguyen and coworkers $^{3,9}$ employed tropylium ion as a Lewis acid catalyst for various transformations like 
acetalization, carbonyl-ene metathesis, O-H insertion of diazoesters, hydroboration, and hydration of alkynes. Decomposition of diazoester followed by the insertion into the X-H bonds has been extensively studied, employing various experimental and computational techniques (Scheme 1). ${ }^{10}$ Several transition metal salts $(\mathrm{Rh}, \mathrm{Cu}, \mathrm{Au}$, etc.) catalyze the decomposition of the diazoesters to provide the corresponding carbenoid species, which then undergoes O-H insertion (Scheme 1a). ${ }^{11}$ Similarly, light-mediated decomposition of diazoesters leading to the corresponding free-carbene is set for a concerted or a stepwise insertion to provide the $\mathrm{O}-\mathrm{H}$ insertion product (Scheme $1 \mathrm{~b}) .{ }^{12}$ The other common pathway for $\mathrm{O}-\mathrm{H}$ insertion is through the Brønsted acid-catalyzed excited-state proton transfer reaction of diazoesters, providing the corresponding diazonium intermediate. Here, the counter-anion initiates an $\mathrm{S}_{\mathrm{N}} 2$ attack on the diazonium intermediate, providing the desired product, albeit with limited substrate scope on the diazoesters (Scheme 1c). ${ }^{13}$ However, under the Lewis acidcatalyzed conditions, coordination of the Lewis acid to the terminal nitrogen of the diazoesters triggers a nucleophilic attack by $\mathrm{R}-\mathrm{OH}$ followed by the release of dinitrogen and the formation of the desired product (Scheme 1d). ${ }^{14}$ In addition to the above pathways, the recently reported tropylium ion catalyzed $\mathrm{O}-\mathrm{H}$ insertion of diazoesters attracted our attention due to its unique reactivity compared to the other pathways (Scheme 1e). ${ }^{3 a}$ We were particularly interested in the coordination modes of tropylium ion and the nature of the activated carbene intermediate bearing a positive charge on the $\mathrm{sp}^{2}$ center. These intriguing features prompted us to deeply study the mechanism and the nature of intermediates involved with the help of density functional theory (DFT) calculations. 
(a) Metal catalyzed $\mathrm{O}-\mathrm{H}$ insertion reaction

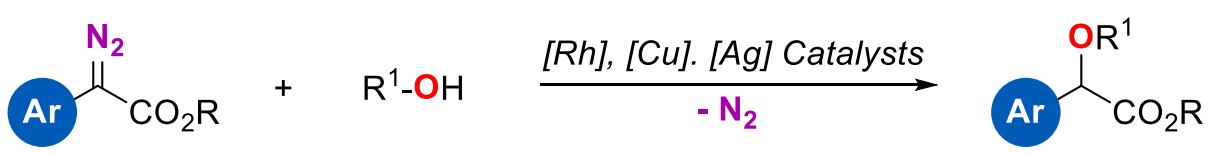

(b) Light-mediated carbene insertion reaction

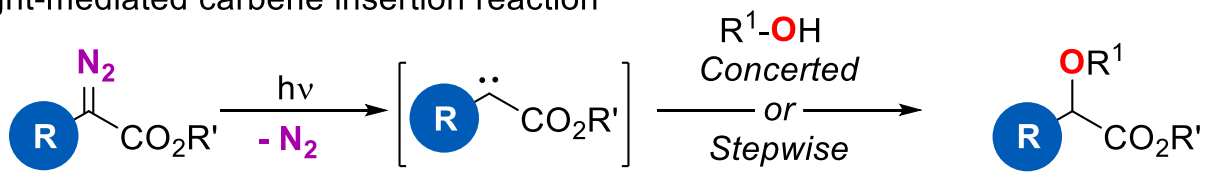

(c) Light-induced protonation- $S_{N} 2$ reaction

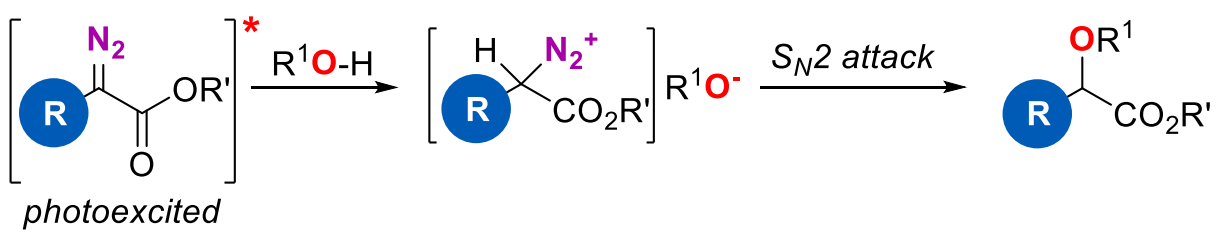

(d) Lewis-Acid catalyzed nucleophilic attack

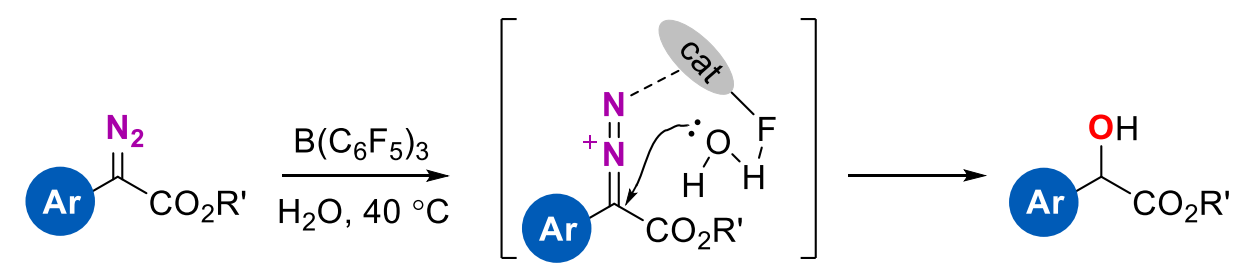

(e) Tropylium ion catalyzed insertion

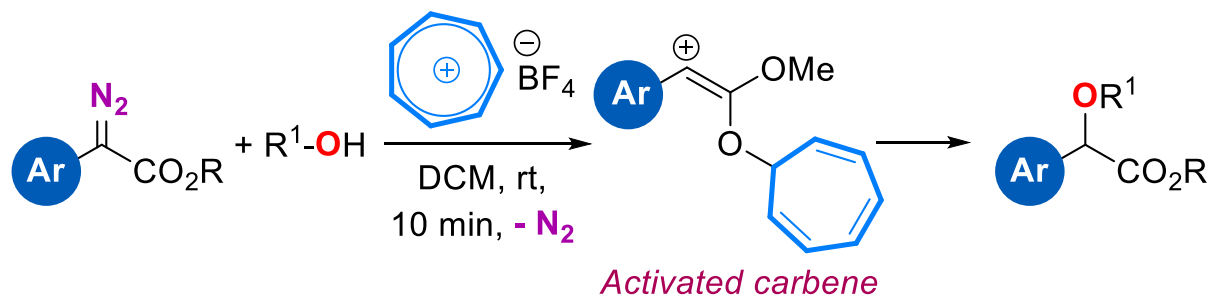

Scheme 1. General pathways for the $\mathrm{O}-\mathrm{H}$ insertion reaction of diazo compounds

\section{Computational Methods}

The geometry optimizations for the intermediates and the transition states were performed in the gas phase at the B97-D3/def2TZVP level of theory ${ }^{15}$ using the Gaussian 16 package. ${ }^{15-16}$ The thermochemistry data for the optimized structures were obtained at the same level of theory. The self-consistent reaction force was applied at the same level of theory using the SMD solvation model with dichloromethane as a solvent to replicate the calculated energies close to the experimental conditions. The stationary points of the intermediates and the 
transition states were characterized based on the number of imaginary vibrational frequencies. All the intermediates presented in the manuscript showed zero imaginary frequency, and the transition states showed a single imaginary frequency on the reaction site. The energies reported in the manuscript are at B97-D3/def2TZVP and B97-D3(SMD)/def2TZVP//B97D3/def2TZVP (in dichloromethane). The sensitivity of the calculations was studied by comparing the reaction energies and barriers from single-point calculations across three levels of theory (BP86(GD3BJ)/def2SVP, B97-D3/def2TZVP; and M06-2X/def2TZVP) on the geometries optimized at B97-D3/def3TZVP. The respective SCF energies and comparison between methods are provided in the supporting information. The molecular planarity parameter (MPP), Bond Length Alteration (BLA) parameters, and the NCI plots were obtained using Multiwfn program version 3.18. ${ }^{17}$ The Wiberg Bond Indices (WBI) were calculated using the NBO3.1 program. $^{18}$ The nuclear independent chemical shifts were calculated at M062X/def2TZVP.

\section{Results and Discussion}

Based on the literature reports, the present study divides the mechanistic plausibility of the O$\mathrm{H}$ insertion of diazoesters into four main approaches: (a) the activated carbene pathway proposed in ref. 3a; (b) homoaromatic intermediate pathway; (c) concerted $\mathrm{O}-\mathrm{H}$ insertion by the carbene ${ }^{12}(\mathrm{~d})$ protonation/nucleophilic attack on the diazoester. ${ }^{14}$

\section{(a) Activated carbene pathway}

First, we discuss our computational results on the reported plausible mechanism for the insertion of benzoic acid into the diazoester (Scheme 2). The pathway involves the coordination of the tropylium ion I to the diazoesters. An equilibrating N-bound tropylium IIa and O-bound tropylium intermediate IIb was proposed. IIb further develops to a corresponding resonance form III. Loss of $\mathrm{N}_{2}$ from the intermediate III was proposed to provide an activated carbene 
IV. Trapping the activated carbene IV with benzoic acid followed by tautomerizations provided the O-H inserted product 3 (Scheme 2).
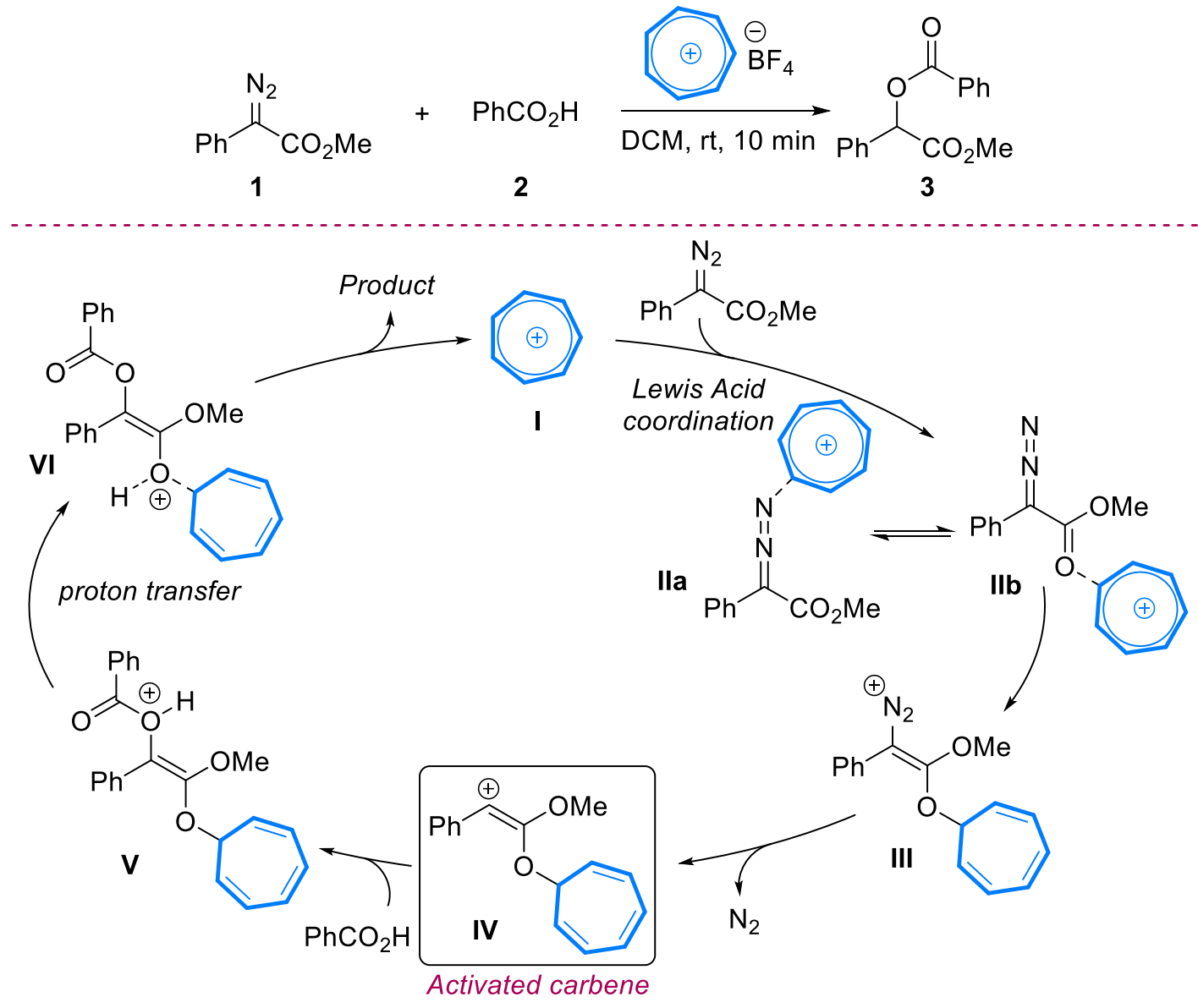

Scheme 2. Proposed tropylium catalyzed pathway for O-H insertion

Our analysis on the diazoester-tropylium complex revealed that the most stable coordination mode was through a charge interaction between the partially negatively charged diazo carbon and the tropylium ring along with a $\pi \cdots \pi$ interaction between the two aromatic rings (tropylium ion and the phenyl ring) as in intermediate A1, in contrast to IIa and IIb. The formation of A1 was endergonic $\left(\Delta \mathrm{G}_{\mathrm{sol}}=+4.2 \mathrm{kcal} / \mathrm{mol}\right)$ compared to the unbound starting materials (Figure 1). The binding of the tropylium ion to the substrate was found to be a charge-dipole interaction in nature, which was evident from the retention of planar geometry of the tropylium ion. The retention of planarity in $\mathbf{A 1}$ can be attributed to the stronger aromatic stabilization possessed by the tropylium ion over the non-aromatic fully bound form. 
(a)

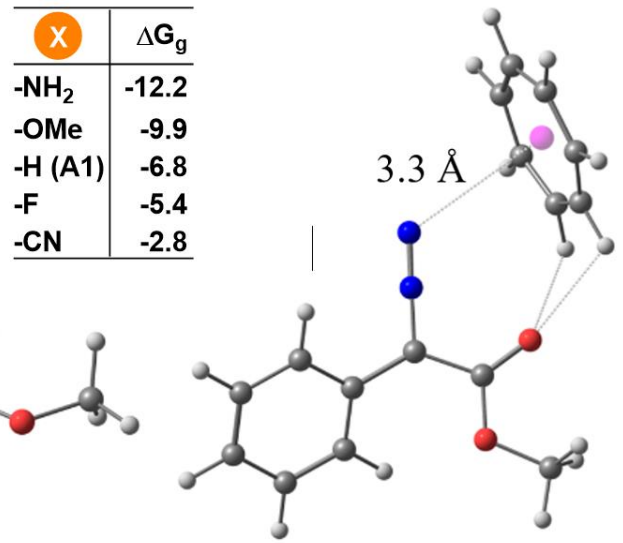

A1a

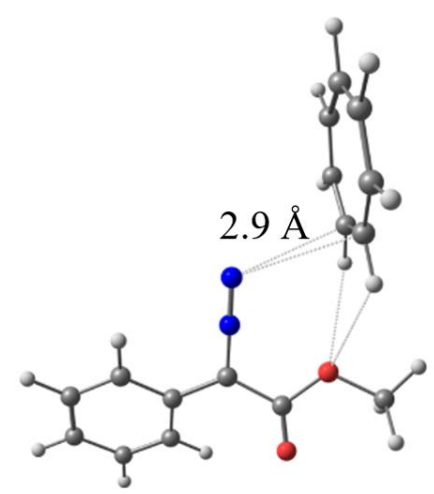

A1b

$+1.5(+8.0)$

$\Delta \mathbf{G}(\mathrm{kcal} / \mathrm{mol})-6.8(+4.2)$

$-2.8(+7.9)$
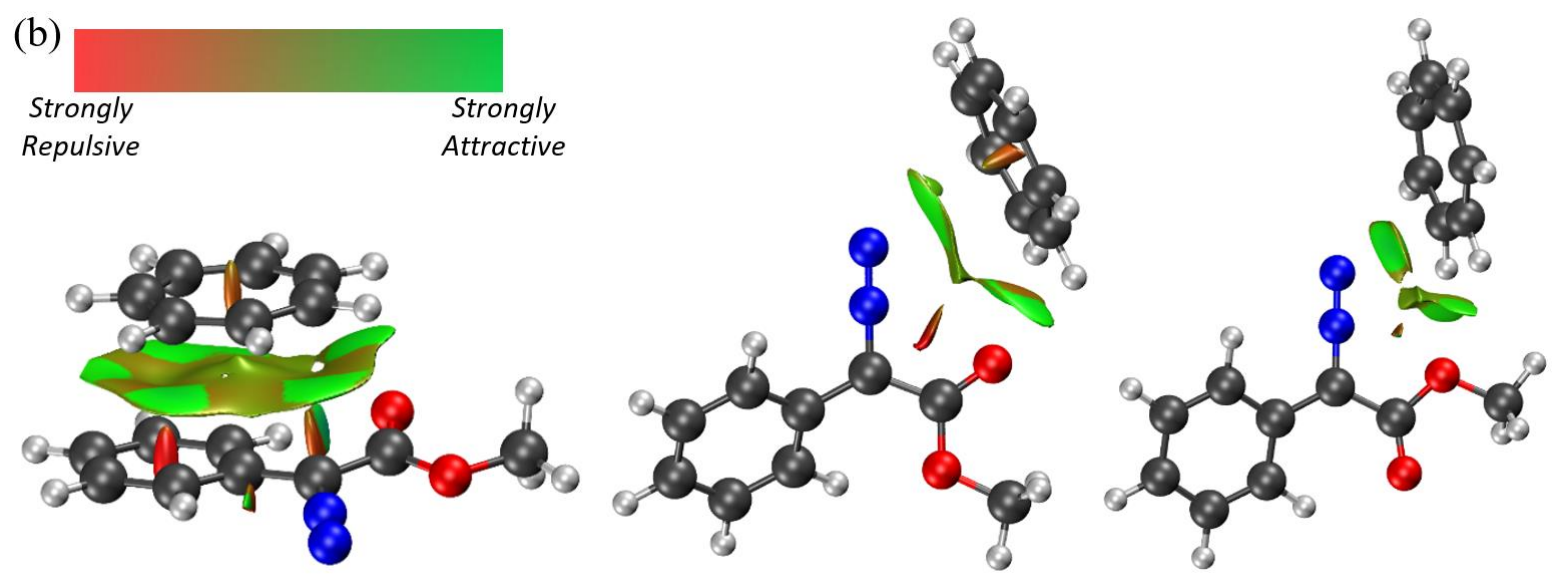

(c)

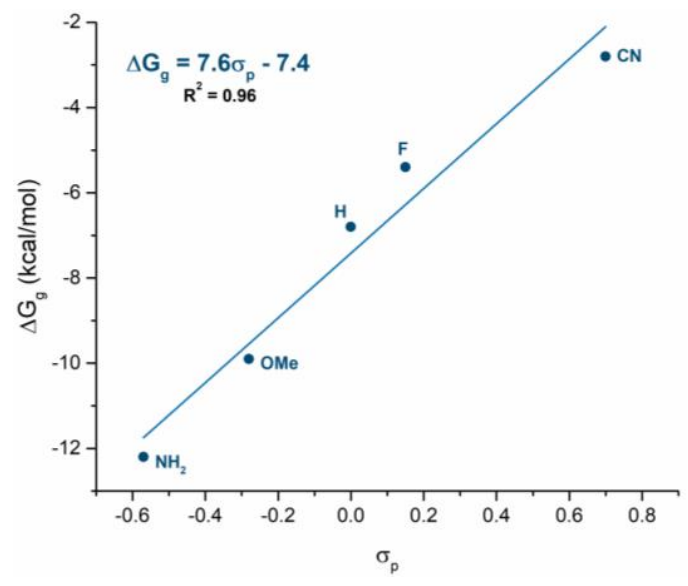

Figure 1. Comparison of the binding mode of diazoester and tropylium ion (A1, A1a, A1b are intermediates). (a) The interaction energies were calculated at B97-D3/def2TZVP and B97D3(SMD)/def2TZVP//B97-D3/def2TZVP (in dichloromethane), respectively. The values in parenthesis are the interaction energies in the solution $(\mathrm{kcal} / \mathrm{mol})$. (b) NCI plots represent noncovalent interactions between two fragments. (c) Correlation plot $\Delta \mathrm{G}$ vs. Hammett substituent constant.

The nature of the interaction was further confirmed by the NCI analysis of A1, which showed a $\pi \cdots \pi$ interaction between the two aromatic rings (Fig. 1). To confirm if the $\pi \cdots \pi$ stacking is 
an artifact of our calculations, we compared the interaction energies of the substituted diazoesters. With electron-donating substituents, the $\pi \cdots \pi$ interactions were strong. However, with electron-withdrawing functionalities, the $\pi \cdots \pi$ interaction was destabilized. The substrate scope reported in the experimental work was restricted to electron-rich diazoesters is noteworthy. ${ }^{3 a}$ The interaction energies of the substituted diazoester showed a linear trend with the Hammett substitution constant. The above trend supports the $\pi \cdots \pi$ interaction between the tropylium cation and the diazoester. The other binding modes (A1a,b) involve terminal nitrogen of the diazo compound and the tropylium ring, and the hydrogen-bonding network of the tropylium $\mathrm{C}-\mathrm{H}$ with the carbonyl oxygen of the ester group was less favorable than $\mathbf{A 1}$. The NCI plots for intermediates A1, A1a, and A1b are presented for comparison in Fig. 1b.

We then turned our attention to model the proposed activated carbene intermediate IV. The uncatalyzed decomposition of diazoester to the corresponding carbene $\mathbf{C} \mathbf{3}$ was an uphill process with a Gibbs free energy change amounting to $+13.7 \mathrm{kcal} / \mathrm{mol}$ (Figure 2 ). The formation of the activated carbene intermediate involved a carbene bearing an oxygen-bound tropylium ion (Scheme 2). However, our attempts to model such a carbene intermediate were unsuccessful. We observed a C, O-bound carbene intermediate A3 formation, although such carbene formation was highly endergonic $\left(\Delta \mathrm{G}_{\mathrm{sol}}=+19.5 \mathrm{kcal} / \mathrm{mol}\right)$. The $\mathbf{A 3}$ could then be trapped by benzoic acid to provide the oxonium intermediate $A 4$ with a $\Delta \mathrm{G}_{\mathrm{sol}}=+19.3 \mathrm{kcal} / \mathrm{mol}$ relative to the starting material (Figure 2). The intermediate $\mathbf{A 4}$ was then proposed to undergo a tautomerization to provide a more stable oxonium species $\mathbf{A 5}$ with $\Delta \mathrm{G}_{\mathrm{sol}}=-1.1 \mathrm{kcal} / \mathrm{mol}$ with respect to the starting materials (Figure 2). Then, A5 was converted to product complex P1 through a subsequent tautomerization. The overall energy profile of the proposed and computationally validated intermediates is given in Figure 2. Comparing the experimental data, a pathway involving such high-energy intermediates (A1 $\rightarrow$ A5; Figure 2) seemed unlikely, which urged us to explore the mechanism closer. 


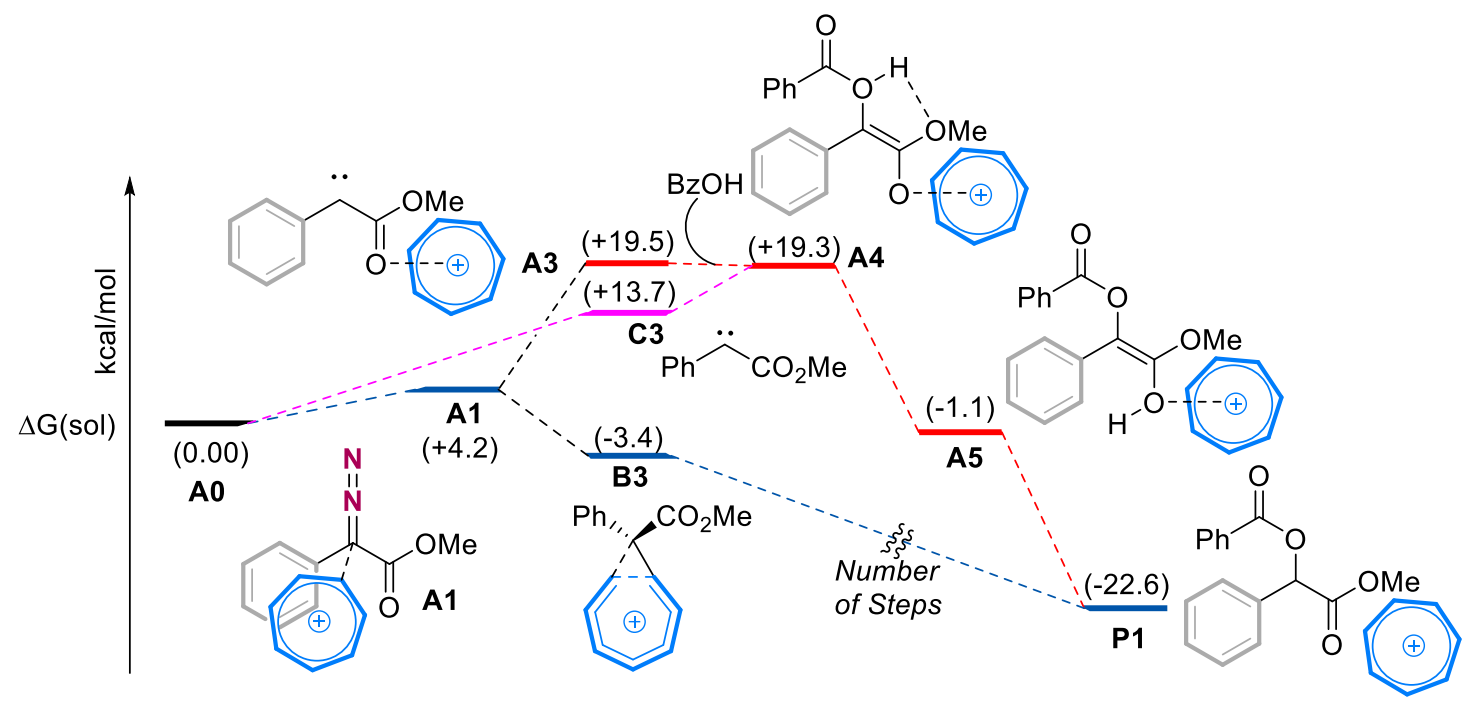

Figure 2. Energy profile of the pathway (a) to $\mathrm{O}-\mathrm{H}$ insertion product and carbene formation. The solution Gibbs free energies (kcal/mol) were obtained at B97-D3(SMD)/def2TZVP//B97D3/def2TZVP (in dichloromethane)

While exploring other possible binding modes of tropylium with carbene, we found the most stable intermediate as the C-bound form $(\mathbf{B 3})$ with a free energy change $\left(\Delta \mathrm{G}_{\mathrm{sol}}\right)$ of $-3.4 \mathrm{kcal} / \mathrm{mol}$ downhill (the respective O-bound species A3 was at $+19.5 \mathrm{kcal} / \mathrm{mol}$ ). The structure exhibited a non-classical three-centered-two-electron $(3 \mathrm{c}-2 \mathrm{e})$ bond involving the tropylium ion through the rupturing of the tropylium ring. Such strong thermodynamic preference and the structural aspects indicated the homoaromatic nature of the C-bound carbene-tropylium intermediate $\mathbf{B 3}$. Tropylium ion mediated reactions with carbenes form homoaromatic intermediates, however this is an unexplored area in catalysis using diazoesters. ${ }^{19}$ In comparison to intermediates $\mathbf{A 3}$ and $\mathbf{C 3}, \mathbf{B 3}$ exhibited remarkable features in terms of bond parameters. The free carbene $\mathbf{C 3}$ exhibited $\mathrm{sp}^{2}$ hybridization with a bond angle of $121.6^{\circ}$, whereas the O-tropylium carbene intermediate $\mathbf{A 3}$ showed $126.5^{\circ}$ (Figure 3). In the newly observed C-bound tropylium carbene intermediate $\mathbf{B 3}$, the elongation of the $\mathrm{C} 13-\mathrm{C} 14$ bond distance and a distortion towards tetrahedral geometry with the reduction in carbene's bond angle $\left(117.8^{\circ}\right)$ were observed (Figure 3). Several attempts to model the activated carbene as proposed provided the stable C-bound or the O-bound tropylium carbene intermediates at the end of the optimizations, thus ruling out the possibility of formation of $\mathbf{I V}$. 


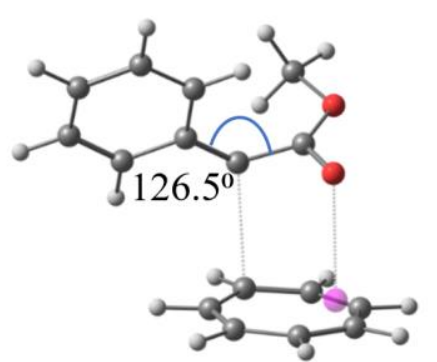

A3

$\Delta \mathbf{G}_{\text {sol }}+19.5(\mathrm{kcal} / \mathrm{mol})$

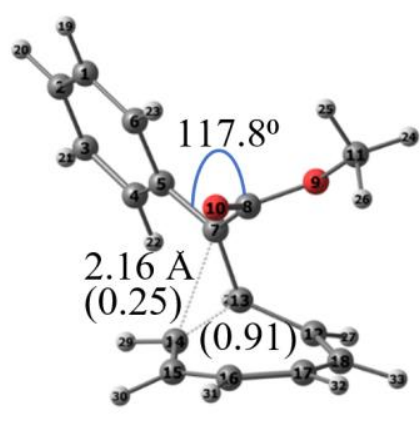

B3

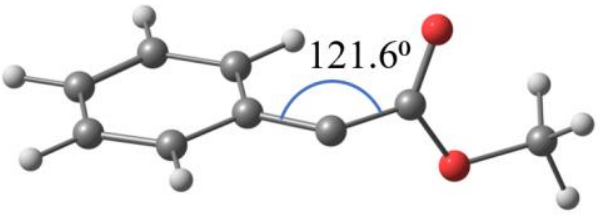

C3

Figure 3. Energetics and the geometry parameters of the carbene intermediates. The solution Gibbs free energies were obtained at B97-D3(SMD)/def2TZVP//B97-D3/def2TZVP (in dichloromethane), geometry parameters were obtained at B97-D3/def2TZVP; The values in parenthesis are the bond orders of C7-C14 and C13-C14 bonds of B3; See SI for enlarged images

\section{(b) Homoaromatic intermediate pathway}

The modeling of the carbene intermediate ruled out the possibility of an activated carbene pathway. The structural characteristic of the newly obtained C-bound tropylium carbene intermediate and its homoaromatic nature encouraged us to study further. Hence, we investigated $\mathbf{B 3}$ as a promising intermediate leading to a new pathway for $\mathrm{O}-\mathrm{H}$ insertion (Scheme 3). A1 was found to be the key intermediates in this reaction (Figure 1). In support of our observation, Mayr and coworkers reported the reaction of tropylium ion with ethyl diazoacetate in the presence of a base to provide the corresponding cycloheptatrienyl diazoester. $^{20}$

In the presence of benzoic acid, a strong complexation of reactants could provide $\mathbf{A} 2$ from $\mathbf{A} \mathbf{1}$ through a network of $\mathrm{O}-\mathrm{H} \cdots \mathrm{O}$ and $\mathrm{C}-\mathrm{H} \cdots \mathrm{O}$ hydrogen bond, diazo-tropylium $\mathrm{C} \cdots \mathrm{C}$ charge interaction, and a $\pi \cdots \pi$ interaction between the two aromatic rings. This 3 -component complex A2 was found to be highly enthalpy driven although disfavored entropically $\left(\Delta \mathrm{G}_{\mathrm{sol}}=+8.7\right.$ $\left.\mathrm{kcal} / \mathrm{mol} ; \Delta \mathrm{H}_{\mathrm{sol}}=-13.0 \mathrm{kcal} / \mathrm{mol}\right)$. Using $\mathbf{A} 2$ as the starting point, we modeled the transition state for the decomposition of the diazoester $\mathbf{1}$ in the presence of tropylium ion $\mathbf{I}$ and benzoic acid 2. Gratifyingly, we obtained the required transition state B2-TS for tropylium catalyzed 
decomposition of the diazoester 1 with an activation barrier of $+29.2 \mathrm{kcal} / \mathrm{mol}$, leading to benzoic acid bound homoaromatic carbene intermediate B4 through a steep exergonic conversion $\left(\Delta \mathrm{G}_{\mathrm{sol}}=-6.3 \mathrm{kcal} / \mathrm{mol}\right)$. From the transition state model B2-TS, the involvement of the $\pi$-bond in displacing the diazonium functionality, paving the way to the homoaromatic intermediate, was evident from the respective bond length and angle of the atoms involved.
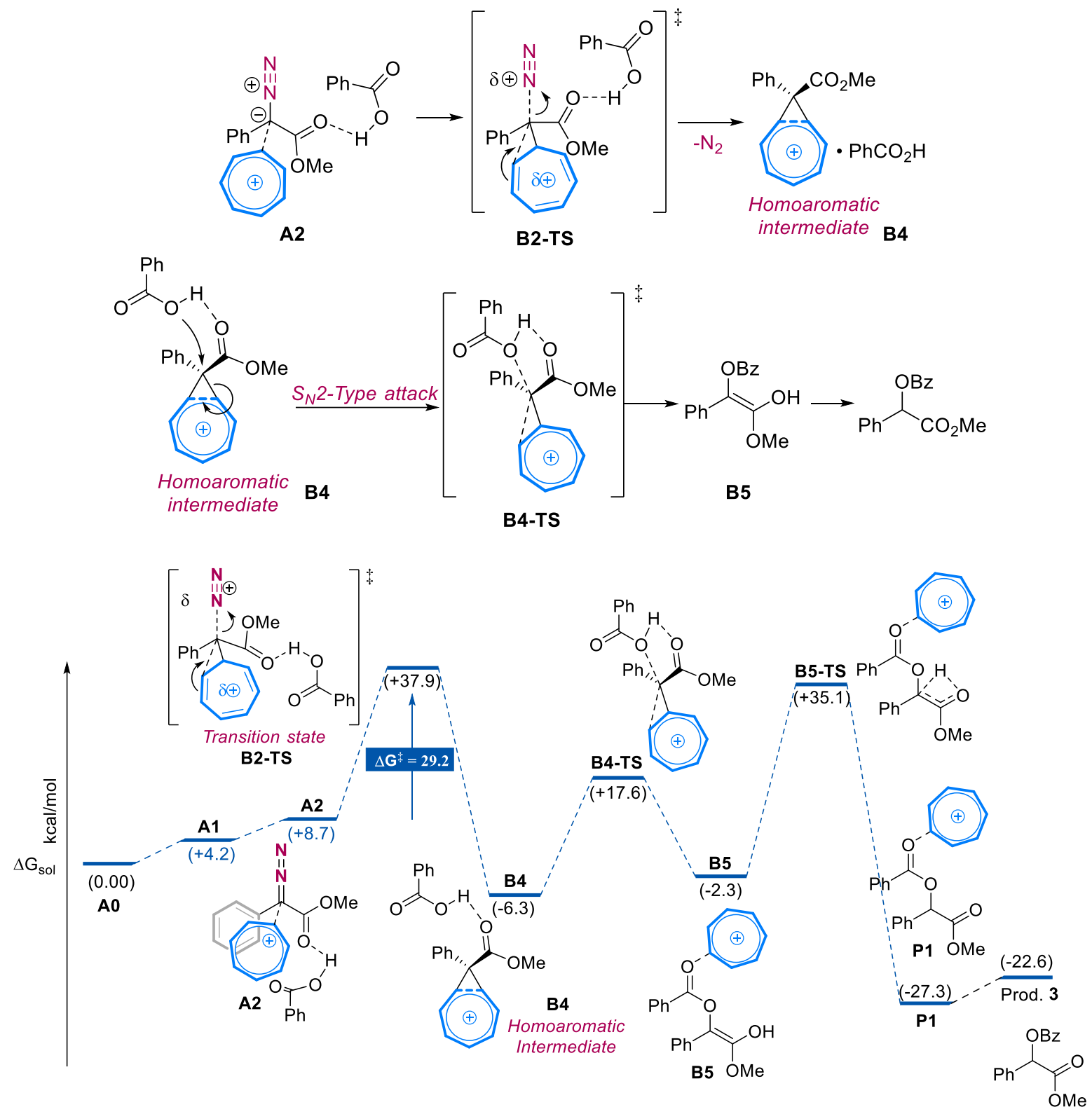

Scheme 3. Homoaromatic intermediate pathway for O-H insertion of diazoesters; The solution Gibbs free energies $(\mathrm{kcal} / \mathrm{mol})$ were obtained at B97-D3(SMD)/def2TZVP//B97D3/def2TZVP (in dichloromethane). 
The partial $\mathrm{C}-\mathrm{C}$ bond cleavage of the tropylium ring is characteristic of a $3 \mathrm{c}-2 \mathrm{e}$ bond intermediate B4 of homoaromatic nature, further confirmed by the molecular orbital analysis and various aromaticity indicators. The Wiberg bond index, bond length alternation, ring current and NICS parameters of B4 were compared against the parent homotropylium ion (Figure 4). The partial sigma bond distance at the ring fusion $[\sigma(r)]$ and the Wiberg indices of B4 and parent homotropylium ion were comparable, suggesting a ring rupturing. The molecular planarity parameter was about $0.18 \AA$ for $\mathbf{B} 4$. The $\operatorname{NICS}_{\mathrm{zz}}(0,1)$ values suggested a diatropic ring current, and the magnetic anisotropy of the parent homotroylium ion and B4 resembled closely up to $5 \AA$ A. The stable homoaromatic intermediate B4 was well set for an $\mathrm{S}_{\mathrm{N}} 2$ attack by the bound benzoic acid to provide the enol intermediate $\mathbf{B 5}$ of the desired product $\mathbf{3}$. We modeled the $S_{\mathrm{N}} 2$ substitution step with benzoic acid 2 , providing the respective transition state B4-TS with a $+23.9 \mathrm{kcal} / \mathrm{mol}$ barrier with respect to the homoaromatic intermediate $\mathbf{B} 4\left(\Delta \mathrm{G}_{\mathrm{sol}}\right.$ $=+17.6 \mathrm{kcal} / \mathrm{mol}$ relative to the starting materials). The transition state B4-TS then leads to the enol intermediate B5. B5 further undergoes tautomerization to provide the product. The homoaromatic intermediate $(\mathrm{A} 2 \rightarrow \mathrm{B} 5)$ pathway seemed more feasible than the activated carbene pathway.

\section{(c) Concerted O-H insertion by the carbene}

Apart from the above pathways, we extended our search to other modes of reactivity of the diazo compounds. We turned our attention towards the concerted insertion of carbene $\mathbf{C 3}$ into the $\mathrm{O}-\mathrm{H}$ bond and the oxonium intermediate formation step. Concerted insertion of carbene across polar X-H has been widely studied previously. ${ }^{12}$ We explored the possibility of such concerted insertion to provide the desired product $\mathbf{3}$ in a single step from carbene $\mathbf{C} \mathbf{3}$ without 
(a)

\begin{tabular}{|ccc|}
\hline Properties & Homotropylium & B4 \\
\hline$\sigma_{(r)}$ & $2.15 \AA$ & $2.13 \AA$ \\
Molecular Planarity Parameter & $0.20 \AA$ & $0.18 \AA$ \\
Bond Length Alternation (BLA) & $0.003 \AA$ & $0.016 \AA$ \\
Wiberg Bond Index & 0.24 & 0.25 \\
NICSzz $(0)^{b}$ & $-23.24 \mathrm{ppm}$ & $-24.55 \mathrm{ppm}$ \\
NICS $z z(1)^{b}$ & $-30.04 \mathrm{ppm}$ & $-30.92 \mathrm{ppm}$ \\
Ring Current & Diatropic & Diatropic \\
\hline
\end{tabular}

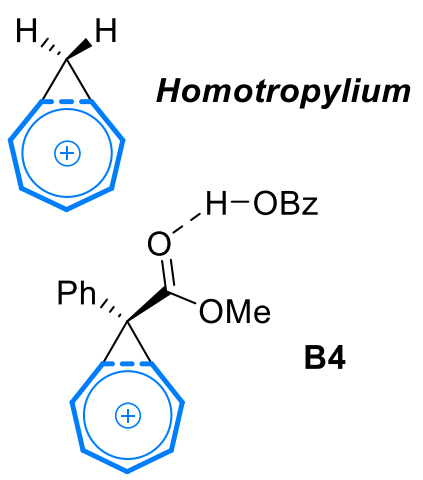

(b)
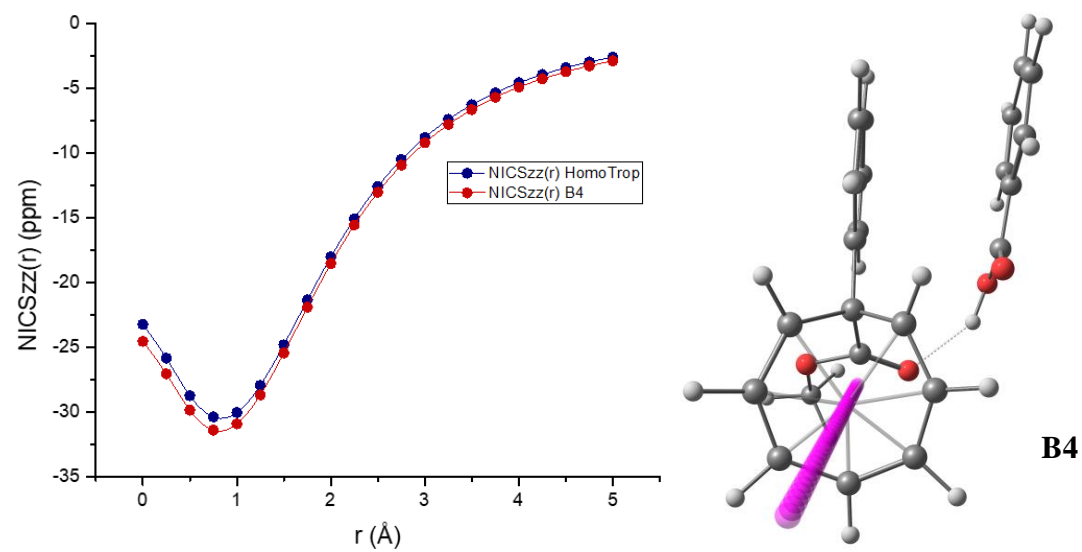

(c)

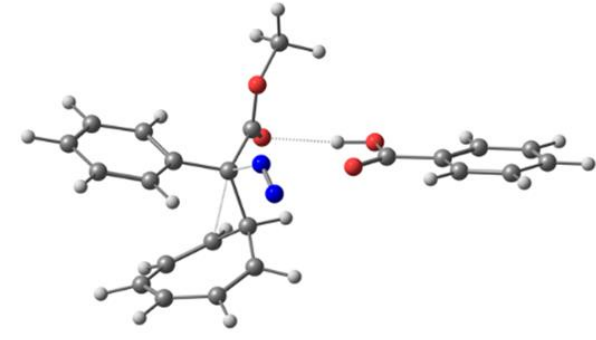

B2-TS
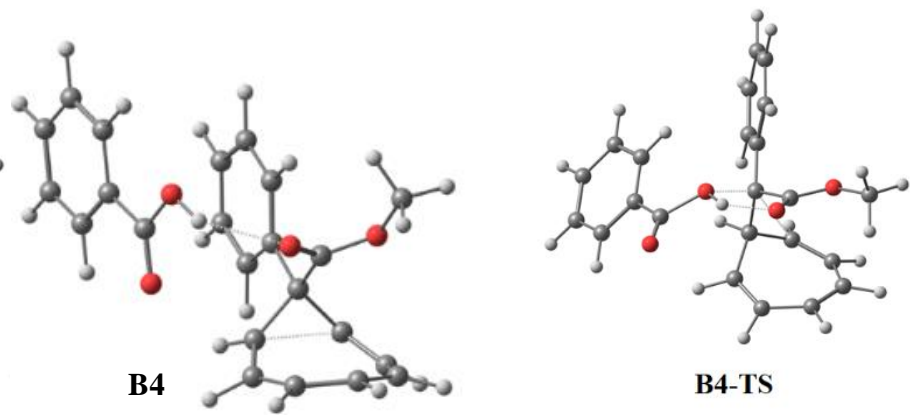

B4-TS

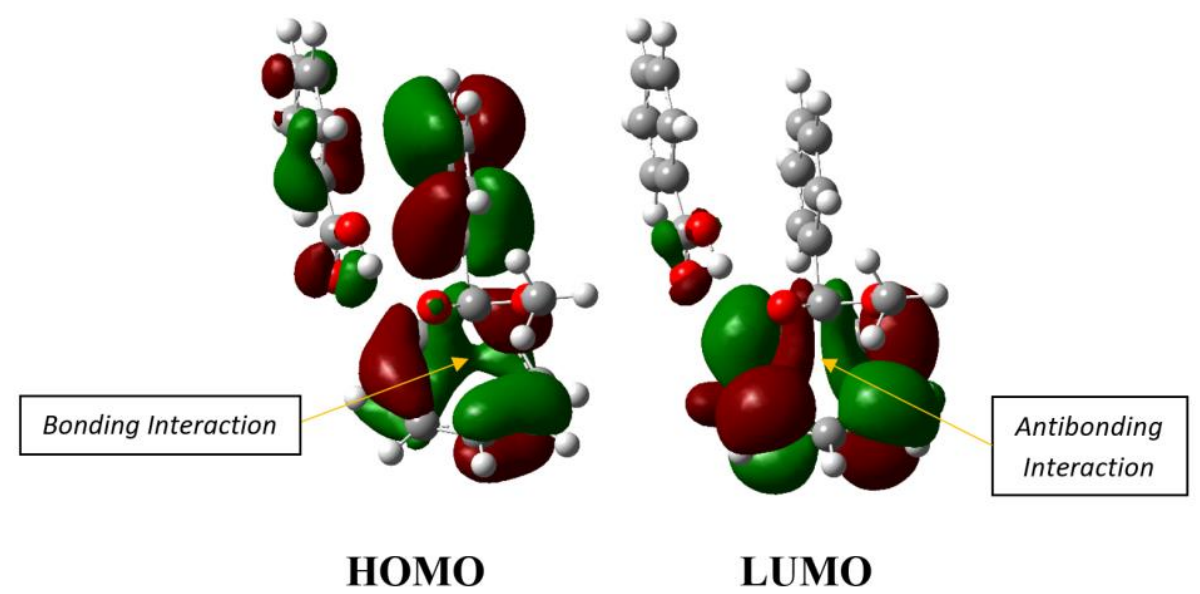

Figure 4. (a) Comparison of B4 and homotroylium ion aromaticity parameters. (b) NICS plots of B4 and the homotroylium ion calculated at M06-2X/def2-TZVP (c) Geometries of transition state B2-TS leading to homoaromatic intermediate B4 and its FMOs, C-O bond formation transition state B4-TS. 
the involvement of a stepwise pathway involving the oxonium intermediates A4 and A5. We modeled the transition state for the insertion of $\mathbf{C 3}$ into the $\mathrm{O}-\mathrm{H}$ bond of benzoic acid $\mathbf{2}$. An overall free energy change $\left(\Delta \mathrm{G}_{\mathrm{sol}}\right)$ of $+45.9 \mathrm{kcal} / \mathrm{mol}$ was observed. The early reactant-like transition state C3-TS developed to a highly exothermic product-tropylium complex formation (Scheme 4). The above parameters showed that such concerted insertion was an energydemanding pathway than the homoaromatic intermediacy route, making the present route less favorable.
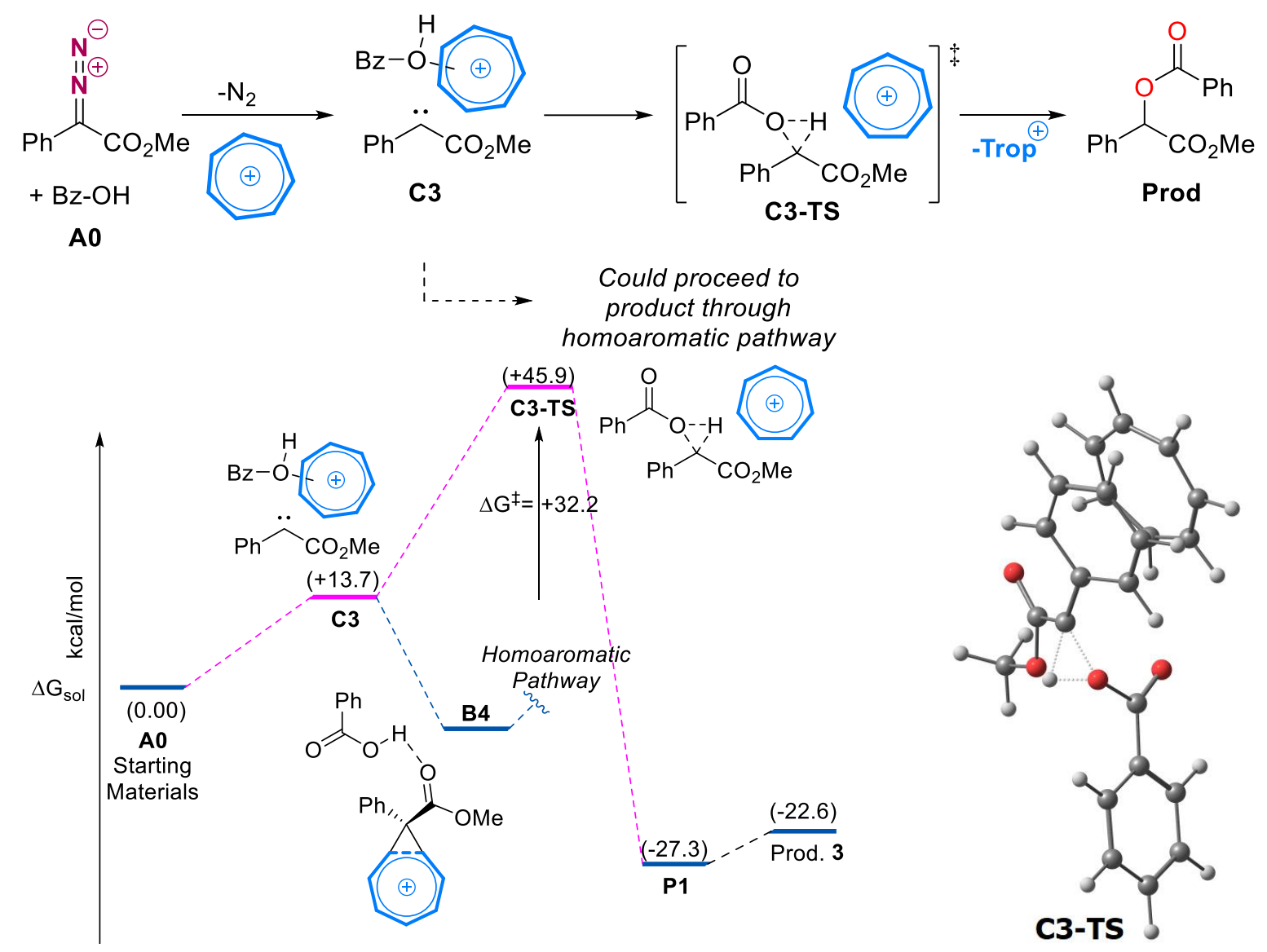

Scheme 4. Carbene formation followed by O-H insertion pathway of diazoesters calculated at B97-D3(SMD)/def2TZVP//B97-D3/def2TZVP (in DCM, kcal/mol).

\section{(d) Protonation/Nucleophilic attack}

Diazo compounds undergo decomposition in the presence of strong acids through the direct protonation of the diazo-carbon to form the diazonium intermediate. However, in the presence of weak acids like benzoic acid, a concomitant protonation/nucleophilic attack was observed, as represented in Scheme 1d. In an attempt to model this pathway, we optimized the protonation 
complex of the diazoester D1, where ester functionality was protonated with benzoic acid. The formation of D1 was an exergonic process $\left(\Delta \mathrm{G}_{\mathrm{sol}}=+5.2 \mathrm{kcal} / \mathrm{mol}\right)$. We envisaged the activation of the terminal nitrogen of the diazoester by tropylium ion followed by a concomitant nucleophilic attack of benzoic acid to the diazo carbon could provide the desired hydrogenbonded transition state D1-TS (Scheme 5). Our calculations revealed that such addition is highly disfavored with a $+39.6 \mathrm{kcal} / \mathrm{mol}$ activation barrier to achieving such a transition state. D1-TS could further transform to the $\mathrm{O}-\mathrm{H}$ inserted product by the expulsion of nitrogen and the catalyst. This pathway could be easily ruled out due to its high barrier.
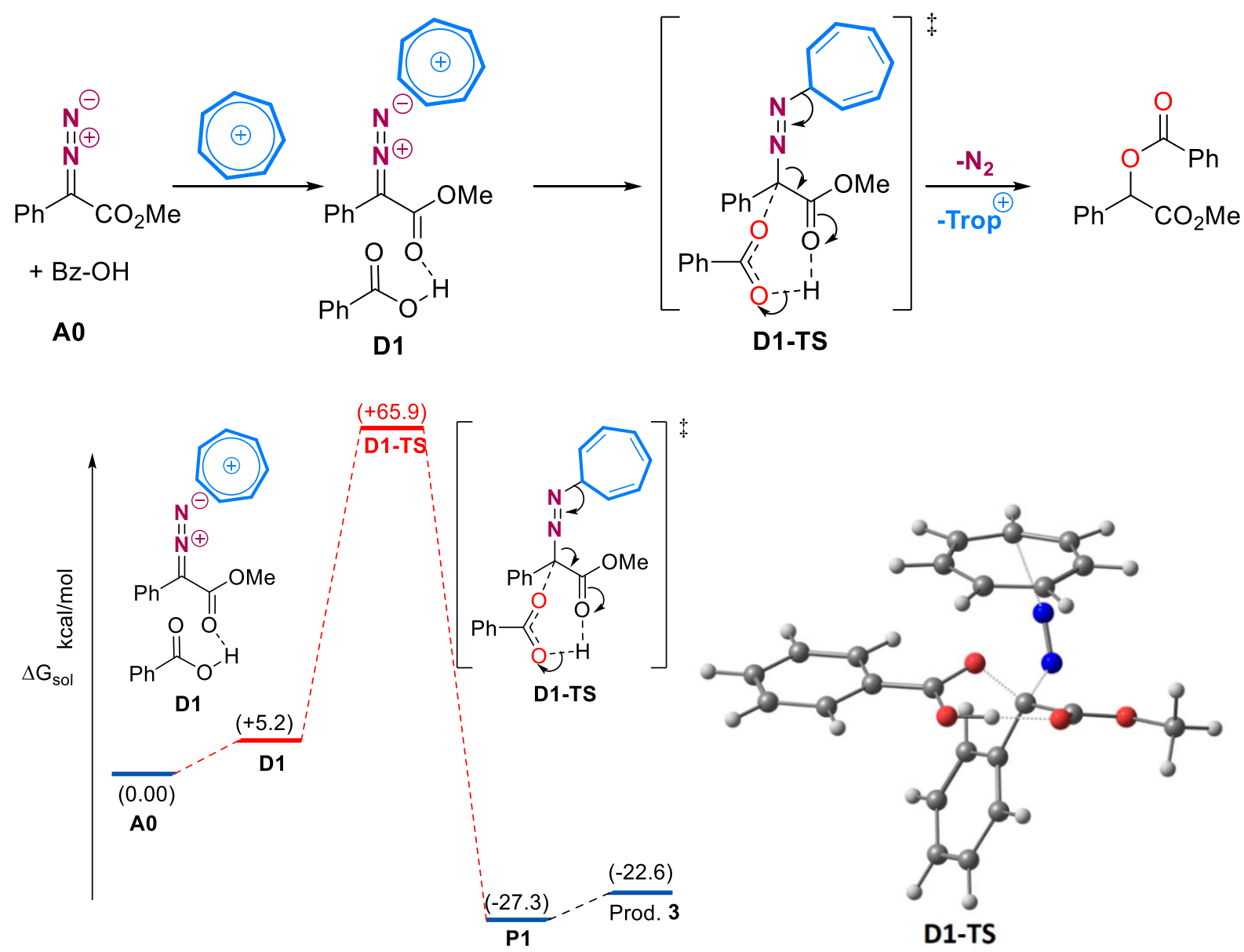

Scheme 5. Nucleophilic addition/O-H insertion pathway of diazoesters. The solution Gibbs free energies $(\mathrm{kcal} / \mathrm{mol})$ were obtained at B97-D3(SMD)/def2TZVP//B97-D3/def2TZVP (in DCM).

To sum up, a comparative energy profile in terms of free energy and enthalpy is provided in Figure 5 for all the considered pathways. From Figure 5, it can be noted that the homoaromatic 
pathway is the lowest energy pathway to the $\mathrm{O}-\mathrm{H}$ inserted product. Considering the feasibility of the above pathways through our DFT studies, we propose the following mechanism for the tropylium catalyzed $\mathrm{O}-\mathrm{H}$ insertion reaction of diazo compounds (Scheme 6). The reaction is initiated by forming a three-component complex $\mathbf{A 2}$ from the diazo compound $\mathbf{1}$ and benzoic acid $\mathbf{2}$ in the presence of a catalytic amount of tropylium ion I. The complex A2 undergoes decomposition to the homoaromatic intermediate $\mathbf{B} 4$ with dinitrogen loss through the transition state B2-TS. B4 is set for an $\mathrm{S}_{\mathrm{N}} 2$ attack by the hydrogen-bonded benzoic acid $\mathbf{2}$ to provide intermediate B5 through the transition state B4-TS. Tautomerization of $\mathbf{B 5}$ could provide the product.

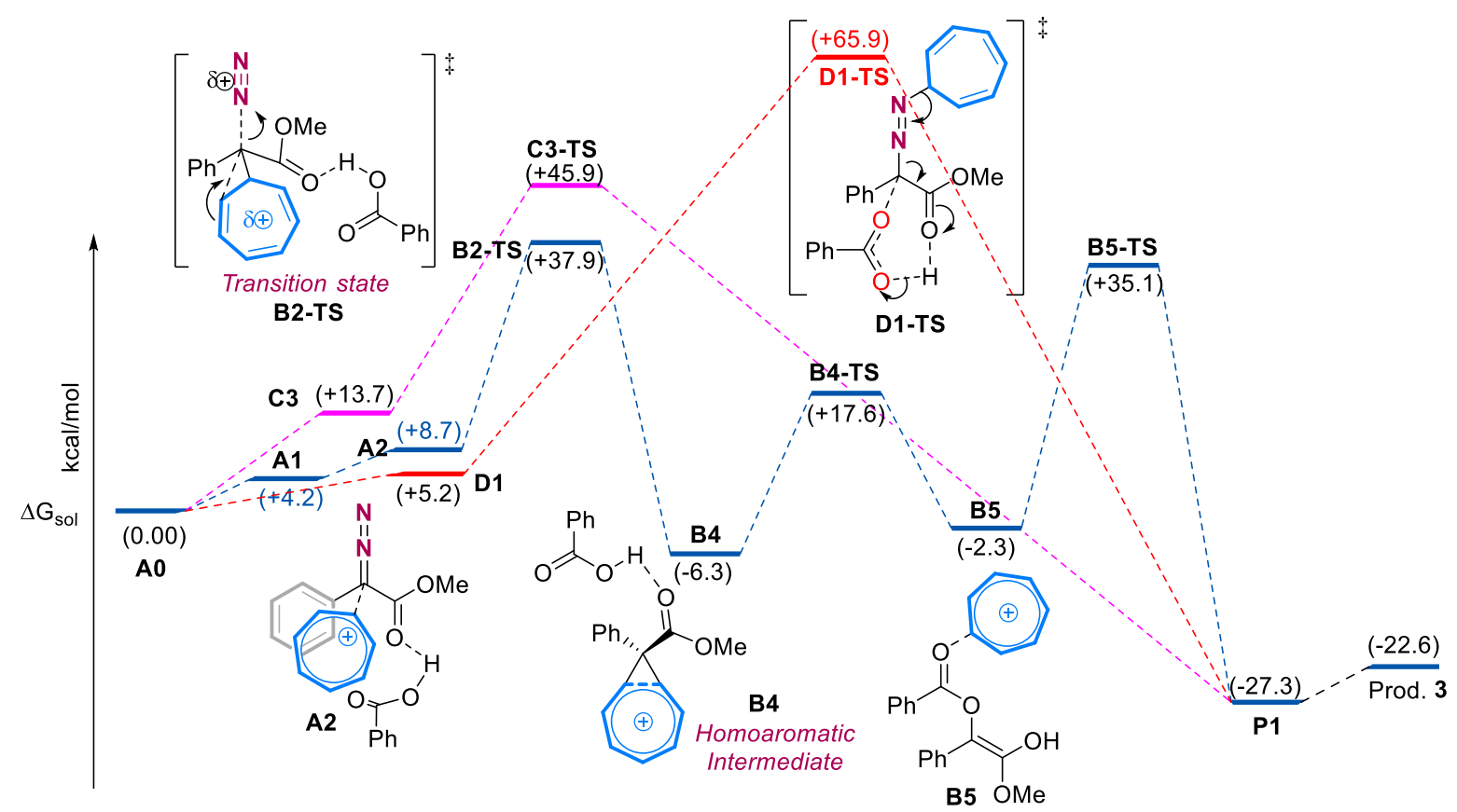

Figure 5. Free-energy profile of pathways (b), (c), and (d) at B97-D3(SMD)/def2TZVP//B97D3/def2TZVP (in dichloromethane, $\mathrm{kcal} / \mathrm{mol}$ ) level. 


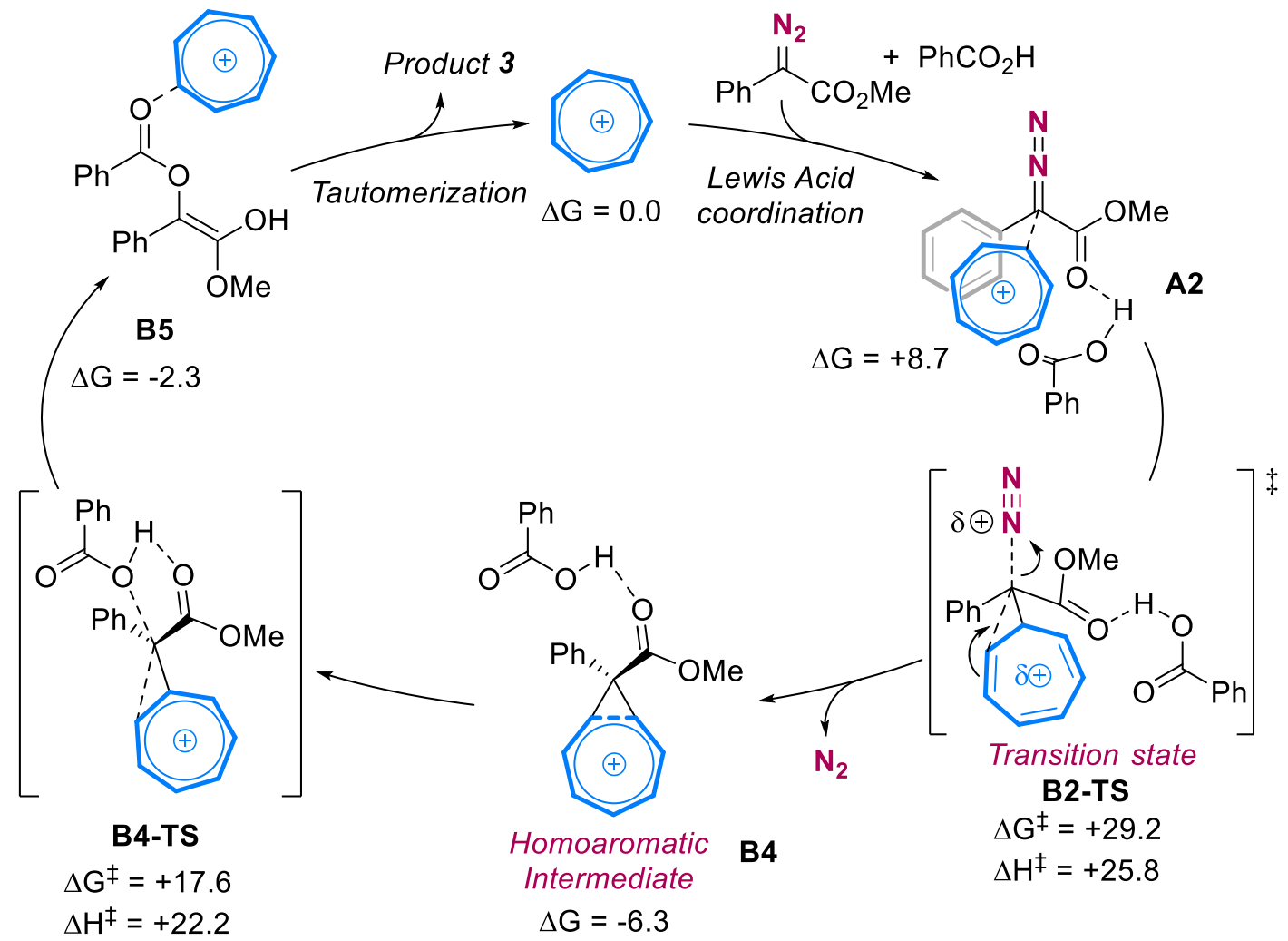

Scheme 6. A revised mechanism for the tropylium ion catalyzed O-H insertion of diazoesters. Free energies (in $\mathrm{kcal} / \mathrm{mol}$ ) provided in the scheme were calculated at B97D3(SMD)/def2TZVP//B97-D3/def2TZVP (in dichloromethane) level.

\section{Conclusions}

We have considered five different routes for the tropylium ion catalyzed $\mathrm{O}-\mathrm{H}$ insertion of diazo compounds viz. (a) the proposed activated carbene pathway; (b) homoaromatic intermediate pathway; (c) concerted $\mathrm{O}-\mathrm{H}$ insertion by the carbene; (d) protonation/nucleophilic attack on the diazoester. In an attempt to model the proposed activated carbene intermediate, we uncovered the homoaromatic nature of the C-bound tropylium carbene intermediate. This key intermediate paved the way for further exploration of decomposition of diazoesters with tropylium ion followed by an $\mathrm{S}_{\mathrm{N}} 2$ attack involving the homoaromatic intermediate. The modeled reaction profile was highly energetically favorable compared to the other pathways considered based on the literature and the previously proposed mechanism. The model supports the experimental observations compared to other pathways in terms of the substrate scope and the energy barrier at room temperature. 


\section{Acknowledgments}

VG thanks the Science and Engineering Research Board (SERB) for the Early Career Research Award (ECR/2018/000944) and the Ramanujan Fellowship (RJN/085/2018). We acknowledge the National Supercomputing Mission (NSM) for providing computing resources of 'PARAM Shakti' at IIT Kharagpur, which is implemented by C-DAC and supported by the Ministry of Electronics and Information Technology (MeitY) and Department of Science and Technology (DST), Government of India.

\section{References}

1. (a) Corma, A.; Garcia, H. Lewis acids: from conventional homogeneous to green homogeneous and heterogeneous catalysis. Chem. Rev. 2003, 103, 4307-65; (b) Walker, J. C. L.; Klare, H. F. T.; Oestreich, M. Cationic silicon Lewis acids in catalysis. Nat. Rev. Chem. 2020, 4, 54-62; (c) Sereda, O.; Tabassum, S.; Wilhelm, R., Lewis Acid Organocatalysts. In Asymmetric Organocatalysis, List, B., Ed. Springer Berlin Heidelberg: Berlin, Heidelberg, 2009; pp 86-117.

2. (a) Lyons, D. J. M.; Crocker, R. D.; Blümel, M.; Nguyen, T. V. Promotion of Organic Reactions by Non-Benzenoid Carbocyclic Aromatic lons. Angew. Chem. Int. Ed. 2017, 56, 1466-1484; (b) An, J.; Denton, R. M.; Lambert, T. H.; Nacsa, E. D. The development of catalytic nucleophilic substitution reactions: challenges, progress and future directions. Org. Biomol. Chem. 2014, 12, 2993-3003; (c) Naidu, V. R.; Ni, S.; Franzén, J. The Carbocation: A Forgotten Lewis Acid Catalyst. ChemCatChem 2015, 7, 1896-1905.

3. (a) Empel, C.; Nguyen, T. V.; Koenigs, R. M. Tropylium-Catalyzed O-H Insertion Reactions of Diazoalkanes with Carboxylic Acids. Org. Lett. 2021, 23, 548-553; (b) Tran, U. P. N.; Oss, G.; Pace, D. P.; Ho, J.; Nguyen, T. V. Tropylium-promoted carbonyl-olefin metathesis reactions. Chem. Sci. 2018, 9, 5145-5151; (c) Lyons, D. J. M.; Crocker, R. D.; Enders, D.; Nguyen, T. V. Tropylium salts as efficient organic Lewis acid catalysts for acetalization and transacetalization reactions in batch and flow. Green Chem. 2017, 19, 3993-3996; (d) Oss, G.; Ho, J.; Nguyen, T. V. Tropylium Ion Catalyzes Hydration Reactions of Alkynes. Eur. J. Org. Chem. 2018, 2018, 3974-3981.

4. Mayr, H.; Ofial, A. R., Electrophilicity Scales for Carbocations. In Carbocation Chemistry, Olah, G. A.; Surya Prakash, G., Eds. Wiley: 2004; pp 331-358.

5. Olah, G. A., 100 Years of Carbocations and their Significance in Chemistry. In Carbocation Chemistry, 2004; pp 7-41.

6. Breslow, R.; Yuan, C. The sym-Triphenylcyclopropenyl Cation, a Novel Aromatic System1. J. Am. Chem. Soc. 1958, 80, 5991-5994.

7. Von E.Doering, W.; Knox, L. H. The Cycloheptatrienylium (Tropylium) Ion. J. Am. Chem. Soc. 1954, 76, 3203-3206.

8. Allen, J. M.; Lambert, T. H. Tropylium ion mediated alpha-cyanation of amines. J. Am. Chem. Soc. 2011, 133, 1260-2.

9. (a) Hussein, M. A.; Huynh, V. T.; Hommelsheim, R.; Koenigs, R. M.; Nguyen, T. V. An efficient method for retro-Claisen-type $\mathrm{C}-\mathrm{C}$ bond cleavage of diketones with tropylium catalyst. Chem. Commun. 2018, 54, 12970-12973; (b) Guo, Y.; Nguyen, T. V.; Koenigs, R. M. Norcaradiene Synthesis via Visible-Light-Mediated Cyclopropanation Reactions of Arenes. Org. Lett. 2019, 21, 8814-8818; (c) Lyons, D. J. M.; Empel, C.; Pace, D. P.; Dinh, A. H.; Mai, B. K.; Koenigs, R. M.; Nguyen, T. V. Tropolonate Salts as Acyl-Transfer Catalysts under Thermal and Photochemical Conditions: Reaction Scope and 
Mechanistic Insights. ACS Catal. 2020, 10, 12596-12606; (d) Omoregbee, K.; Luc, K. N. H.; Dinh, A. H.; Nguyen, T. V. Tropylium-promoted prenylation reactions of phenols in continuous flow. J. Flow Chem. 2020, 10, 161-166; (e) Ton, N. N. H.; Mai, B. K.; Nguyen, T. V. Tropylium-Promoted Hydroboration Reactions: Mechanistic Insights Via Experimental and Computational Studies. J. Org. Chem. 2021, 86, 9117-9133.

10. (a) Miller, D. J.; Moody, C. J. Synthetic Applications of the O-H Insertion Reactions of Carbenes and Carbenoids Derived from Diazocarbonyl and Related Diazo-Compounds. Tetrahedron 1995, 51, 10811-10843; (b) Doyle, M. P.; Trudell, M. L. Catalytic Role of Copper Triflate in Lewis Acid Promoted Reactions of Diazo-Compounds. J. Org. Chem. 1984, 49, 1196-1199; (c) Muthusamy, S.; Babu, S. A.; Gunanathan, $\mathrm{C}$. Indium triflate: a mild and efficient Lewis acid catalyst for $\mathrm{O}-\mathrm{H}$ insertion reactions of a-diazo ketones. Tetrahedron Lett. 2002, 43, 3133-3136; (d) Liu, Y.; Luo, Z.; Zhang, J. Z.; Xia, F. DFT Calculations on the Mechanism of Transition-Metal-Catalyzed Reaction of Diazo Compounds with Phenols: O-H Insertion versus C-H Insertion. J. Phys. Chem. A 2016, 120, 6485-92; (e) Li, F.; Zhang, J. Z.; Xia, F. How CuCl and $\mathrm{CuCl} 2$ Insert into C-N Bonds of Diazo Compounds: An Electronic Structure and Mechanistic Study. J. Phys. Chem. A 2020, 124, 2029-2035.

11. (a) Pereira, A.; Champouret, Y.; Martín, C.; Álvarez, E.; Etienne, M.; Belderraín, T. R.; Pérez, P. J. Copper-Carbene Intermediates in the Copper-Catalyzed Functionalization of O-H Bonds. Chem. Eur. J. 2015, 21, 9769-9775; (b) Bulugahapitiya, P.; Landais, Y.; Parra-Rapado, L.; Planchenault, D.; Weber, V. A Stereospecific Access to Allylic Systems Using Rhodium(II)-Vinyl Carbenoid Insertion into $\mathrm{Si}-\mathrm{H}, \mathrm{O}-\mathrm{H}$, and N-H Bonds. J. Org. Chem. 1997, 62, 1630-1641; (c) Gillingham, D.; Fei, N. Catalytic X$\mathrm{H}$ insertion reactions based on carbenoids. Chem. Soc. Rev. 2013, 42, 4918-4931; (d) Liang, Y.; Zhou, H.; Yu, Z.-X. Why Is Copper(I) Complex More Competent Than Dirhodium(II) Complex in Catalytic Asymmetric $\mathrm{O}-\mathrm{H}$ Insertion Reactions? A Computational Study of the Metal Carbenoid O-H Insertion into Water. J. Am. Chem. Soc. 2009, 131, 17783-17785; (e) Zhang, Z.; Wang, J. Recent studies on the reactions of $\alpha$-diazocarbonyl compounds. Tetrahedron 2008, 64, 6577-6605; (f) Zhou, L.; Liu, Y.; Zhang, Y.; Wang, J. Sequential $\mathrm{Au}(\mathrm{I})$-catalyzed reaction of water with o-acetylenyl-substituted phenyldiazoacetates. Beilstein J. Org. Chem. 2011, 7, 631-637; (g) Zhu, S.-F.; Cai, Y.; Mao, H.-X.; Xie, J.-H.; Zhou, Q.-L. Enantioselective iron-catalysed O-H bond insertions. Nat. Chem. 2010, 2, 546-551; (h) Zhu, S.-F.; Zhou, Q.-L. Transition-Metal-Catalyzed Enantioselective Heteroatom-Hydrogen Bond Insertion Reactions. Acc. Chem. Res. 2012, 45, 1365-1377.

12. Yang, Z.; Stivanin, M. L.; Jurberg, I. D.; Koenigs, R. M. Visible light-promoted reactions with diazo compounds: a mild and practical strategy towards free carbene intermediates. Chem. Soc. Rev. 2020, 49, 6833-6847.

13. (a) Shields, S. W. J.; Manthorpe, J. M. Efficient, scalable and economical preparation of tris(deuterium)- and $13 \mathrm{C}$-labelled $\mathrm{N}$-methyl- $\mathrm{N}$-nitroso-p-toluenesulfonamide (Diazald ${ }^{\circledR}$ ) and their conversion to labelled diazomethane. J. Labelled Compd. Radiopharm. 2014, 57, 674-679; (b) Kühnel, E.; Laffan, D. D. P.; Lloyd-Jones, G. C.; Martínez del Campo, T.; Shepperson, I. R.; Slaughter, J. L. Mechanism of Methyl Esterification of Carboxylic Acids by Trimethylsilyldiazomethane. Angew. Chem. Int. Ed. 2007, 46, 7075-7078; (c) Empel, C.; Jana, S.; Pei, C.; Nguyen, T. V.; Koenigs, R. M. Photochemical O-H Functionalization of Aryldiazoacetates with Phenols via Proton Transfer. Org. Lett. 2020, 22, 7225-7229; (d) Empel, C.; Verspeek, D.; Jana, S.; Koenigs, R. M. Photochemical O-H Functionalization Reactions of Cyclic Diazoamides. Adv. Synth. Catal. 2020, 362, 4716-4722.

14. (a) San, H. H.; Wang, S. J.; Jiang, M.; Tang, X. Y. Boron-Catalyzed O-H Bond Insertion of alphaAryl alpha-Diazoesters in Water. Org. Lett. 2018, 20, 4672-4676; (b) Babaahmadi, R.; Dasgupta, A.; Hyland, C. J. T.; Yates, B. F.; Melen, R.; Ariafard, A. Understanding the Influence of Donor-Acceptor Diazo Compounds on the Catalyst Efficiency of $\mathrm{B}(\mathrm{C} 6 \mathrm{F5}) 3$ Towards Carbene Formation. Chem. Eur. J. 2021, DOI: 10.1002/chem.202104376.

15. Goerigk, L.; Hansen, A.; Bauer, C.; Ehrlich, S.; Najibi, A.; Grimme, S. A look at the density functional theory zoo with the advanced GMTKN55 database for general main group thermochemistry, kinetics and noncovalent interactions. Phys. Chem. Chem. Phys. 2017, 19, 3218432215. 
16. Frisch, M. J.; Trucks, G. W.; Schlegel, H. B.; Scuseria, G. E.; Robb, M. A.; Cheeseman, J. R.; Scalmani, G.; Barone, V.; Petersson, G. A.; Nakatsuji, H.; Li, X.; Caricato, M.; Marenich, A. V.; Bloino, J.; Janesko, B. G.; Gomperts, R.; Mennucci, B.; Hratchian, H. P.; Ortiz, J. V.; Izmaylov, A. F.; Sonnenberg, J. L.; Williams-Young, D.; Ding, F.; Lipparini, F.; Egidi, F.; Goings, J.; Peng, B.; Petrone, A.; Henderson, T.; Ranasinghe, D.; Zakrzewski, V. G.; Gao, J.; Rega, N.; Zheng, G.; Liang, W.; Hada, M.; Ehara, M.; Toyota, K.; Fukuda, R.; Hasegawa, J.; Ishida, M.; Nakajima, T.; Honda, Y.; Kitao, O.; Nakai, H.; Vreven, T.; Throssell, K.; Jr., J. A. M.; Peralta, J. E.; Ogliaro, F.; Bearpark, M. J.; Heyd, J. J.; Brothers, E. N.; Kudin, K. N.; Staroverov, V. N.; Keith, T. A.; Kobayashi, R.; Normand, J.; Raghavachari, K.; Rendell, A. P.; Burant, J. C.; Iyengar, S. S.; Tomasi, J.; Cossi, M.; Millam, J. M.; Klene, M.; Adamo, C.; Cammi, R.; Ochterski, J. W.; Martin, R. L.; Morokuma, K.; Farkas, O.; Foresman, J. B.; Fox, D. J. Gaussian 16, Revision B.01, Gaussian, Inc., Wallingford CT, 2016.

17. Lu, T.; Chen, F. Multiwfn: A multifunctional wavefunction analyzer. J. Comput. Chem. 2012, 33, 580-592.

18. Glendening, E. D.; Badenhoop, J. K.; Reed, A. E.; Carpenter, J. E.; Bohmann, J. A.; Morales, C. M.; Karafiloglou, P.; Landis, C. R.; Weinhold, F., Theoretical Chemistry Institute, University of Wisconsin, Madison. 2018.

19. (a) Childs, R. F. The homotropylium ion and homoaromaticity. Acc. Chem. Res. 1984, 17, 347352; (b) Winstein, S. Centenary Lecture. Nonclassical ions and homoaromaticity. Q. Rev. Chem. Soc. 1969, 23, 141-176.

20. Bug, T.; Hartnagel, M.; Schlierf, C.; Mayr, H. How Nucleophilic Are Diazo Compounds? Chem. Eur. J. 2003, 9, 4068-4076. 